\title{
The paradox of the 2 Ist century - is there really an epidemic of most common killers?
}

This article was published in the following Dove Press journal:

International Journal of General Medicine

28 November 201I

Number of times this article has been viewed

\section{Leszek Paczek \\ Marcin Nowak}

Transplantation Institute, Department of Immunology, Transplantology and Internal Diseases, Medical University of Warsaw, Warsaw, Poland
Correspondence: Leszek Paczek, Transplantation Institute, Department of Immunology, Transplantology and Internal Diseases, Medical University of Warsaw, ul. Nowogrodzka 59, 02-006 Warsaw, Poland

Tel +48507 I2। 346

Email leszek.paczek@wum.edu.pl
Abstract: Over the last 110 years, average global life expectancy has more than doubled from 31 years of age to 65 years of age. This trend is expected to continue, and many of the children born after the year 2000 can expect to live to celebrate their hundredth birthday. In the last 20 years alone, average life expectancy has increased globally by 6 years.

During the same period, doctors have announced a global epidemic of the most common killers: cardiovascular disease, diabetes, chronic kidney, and chronic obstructive pulmonary disease. One of the most important reasons for the more frequent recognition of these diseases is the fact that their diagnostic criteria have changed and become much more acute during the past few years.

These changes in diagnostic criteria have made it difficult, or even impossible, to compare the present statistical data regarding these diseases to historical data for the same illnesses. Due to this difficulty, there is no evidence-based comparison of the prevalence of any disease at present and in the past. Before announcing a global epidemic, a fair epidemiological comparison should be made, based upon the same definitions and using identical diagnostic tools.

Keywords: global life expectancy, epidemic of CVD, DM, CKD, COPD

An epidemic (epi- meaning "upon or above" and demos- meaning "people") occurs when new cases of a certain disease, in a given population, and during a given period, substantially exceed what is expected based on recent experience. It may be restricted to one locale, or it may be global, in which case it is called a pandemic. ${ }^{1}$ In the following article, the term "epidemic" will be used to refer to an actual increase in disease prevalence.

Life expectancy at birth reflects the overall mortality level of a population. It also summarizes the mortality pattern that prevails across different age groups in a given year - children, adolescents, adults, and the elderly.

In 1900, the global average life expectancy was 31 years of age, and did not exceed 50 years in even the richest countries. By the mid-twentieth century, the average life expectancy had risen to 48 years. In 2005, the global average lifespan exceeded 65 years, and in some countries even 80 years. By 2030, the average life expectancy in the richest countries will have risen to 85 years. Many of the children born after 2000 will live to celebrate their hundredth birthday. ${ }^{2}$

Historically, infectious diseases have long been the leading cause of death and disability. This was particularly evident among children and affected mainly the poorest populations in the poorest countries. The constant progress of medicine has led to the complete eradication of smallpox, and the virtual eradication of leprosy and polio is expected in the next few years. Vaccines against the six killer diseases of childhood have been invented. Measles deaths were cut by 48\% between 1994 and 2004. The risk 
of death for children less than 5 years of age is projected to fall by over $40 \%$ in the next 25 years.

These successes have generated a transition to societies with rapidly increasing numbers of middle-aged and elderly. As a result, a different set of diseases has come into prominence: cancers, cardiovascular diseases, and mental illnesses, all with less impressive treatment results in comparison to infectious diseases.

As life expectancy increases, the major causes of death and disability shift from childhood diseases to non-infectious, chronic illnesses in adulthood. Chronic diseases cause almost 35 million (60\%) deaths a year. Cardiovascular diseases kill as many people as all infectious diseases combined. Almost $50 \%$ of all chronic disease deaths occur in people under 70 years of age. $80 \%$ of these deaths are in developing countries.

In 2005 an estimated 58 million people died worldwide. The main causes of death were: cardiovascular diseases $(29.3 \%)$, including ischemic heart disease (12.7\%) and stroke (9.7\%); infectious diseases (23.0\%); cancers (12.5\%); respiratory diseases $(6.5 \%)$; including chronic obstructive pulmonary disease $(4.8 \%)$; unintentional injuries $(6.2 \%)$; including road traffic accidents $(2.1 \%)$; diabetes $(1.7 \%){ }^{3}$

The data indicates that in the beginning of the 20th century, cardiovascular disease (CVD) was responsible for less than $10 \%$ of all deaths worldwide, but by 2001 that figure was $30 \%$. About $80 \%$ of the global burden of CVD death occurs in developing countries. By 2001, CVD had become the leading cause of death in the developing world, as it has been in the developed world since the mid-1900s. CVD is expected to become the leading cause of death and disability worldwide by 2020 primarily due to an increase in poorer countries. Nearly $50 \%$ of all deaths in high-income countries, and about $28 \%$ of deaths in developing countries, are the result of CVD. ${ }^{4}$

According to current scientific literature, diabetes mellitus (DM) prevalence is increasing in every country in the world. Currently, 285 million people, or approximately $6.4 \%$ of the world's adult population, live with diabetes. By 2030, this number is expected to grow to 439 million. ${ }^{5}$ Worldwide, only half of all people with diabetes are diagnosed. ${ }^{6}$ Unless diabetes prevention, early diagnosis, and treatment are drastically improved, the world faces a global pandemic. In the developing world, type 2 diabetes may account for more than $95 \%$ of all diabetes cases. ${ }^{7}$

The number of patients with chronic kidney disease (CKD), and the subsequent need for renal replacement therapy, has reached epidemic proportion and is anticipated to rise further. Worldwide, it is estimated that over 1.1 million patients with end-stage renal disease currently require maintenance dialysis, and this number is increasing at a rate of $7 \%$ per year. ${ }^{8}$

Chronic obstructive pulmonary disease (COPD) is the fourth leading cause of death in the world, with approximately 2.75 million deaths per year, or $4.8 \%$ of deaths. ${ }^{3}$ COPD is responsible for early mortality, high death rates and significant cost to health systems. The projection for 2020 indicates that COPD will be the third leading cause of death worldwide (from sixth in 1990), and fifth leading cause of years lost through early mortality or handicap (twelfth in 1990). ${ }^{9}$

Keeping all the above in mind, we would like to point out that during the last 20 years average life expectancy has increased globally by 6 years. ${ }^{1}$ In the same period, doctors have announced a global epidemic of the most common killers: CVD, DM, CKD and COPD. One of the most important reasons for the more frequent recognition of the above diseases is the fact that their diagnostic criteria have changed to become much more acute during the past few years.

Traditionally, myocardial infarction (MI) was diagnosed according to the 1971 WHO criteria based on the clinical syndrome, electrocardiography (ECG) changes, and the increase of relatively non-specific markers of myocardial damage such as creatine kinase $(\mathrm{CK}) .{ }^{10}$ The first global definition of MI was published in 2000 and was based upon muscle and brain (iso-enzyme) of creatine kinase (CK-MB) mass and troponin. These criteria are very specific and sensitive biological markers of myocardial ischemia. ${ }^{11}$ The new definition included clinical data and typical ischemic changes in ECG. Another global definition, called a universal definition of myocardial infarction, appeared in $2007 .{ }^{12}$ It was much broader in comparison to the definition from 2000, (included more clinical situations in which the doctors could establish the diagnosis of MI) so it must have expanded the group of people diagnosed with MI and ischemic heart disease. The use of this universal definition has many social and epidemiologic implications (increased reporting).

The WHO published the first classification of diabetes in 1980 and, in modified form, in $1985 .{ }^{13}$ The second classification was widely accepted and used internationally. In 1997, an international expert committee released a report with new recommendations for the classification and diagnosis of diabetes. ${ }^{14}$ New diagnostic criteria for diabetes, including a lower cutoff for fasting plasma glucose levels $(126 \mathrm{mg} / \mathrm{dL})(7 \mathrm{mmol} / \mathrm{L})$ instead of $140 \mathrm{mg} / \mathrm{dL}(7.8 \mathrm{mmol} / \mathrm{L})$ must have greatly increased the number of people diagnosed with this disease. If the cutoff is 
further decreased, for instance to $120 \mathrm{mg} / \mathrm{dL}$ in 2020 , it will obviously increase the reporting of diabetes (Figure 1).

In 2002, the National Kidney Foundation defined chronic kidney disease (CKD) for the first time as a disorder lasting 3 or more months with either kidney damage defined by structural or functional abnormalities, or an estimated glomerular filtration rate (GFR) of less than $60 \mathrm{~mL} /$ minute/1.73 $\mathrm{m}^{2}{ }^{2}{ }^{15,16}$ The GFR is considered the best measure of overall kidney function and it physiologically declines with age. ${ }^{17}$ A GFR level below $60 \mathrm{~mL} / \mathrm{minute} / 1.73 \mathrm{~m}^{2}$ represents a loss of at least half of the adult level of normal kidney function. Because of the age-related decline in GFR, the prevalence of chronic kidney disease increases with age. Approximately $17 \%$ of persons over 60 years have an estimated GFR (eGFR) of less than $60 \mathrm{~mL} /$ minute $/ 1.73 \mathrm{~m}^{2} .{ }^{18}$ The rise in diagnosis of chronic kidney disease is multifactorial but associated with the ageing population. As technology and medical interventions improve, life spans increase, which has an effect on chronic disease populations. The incidence of diabetes has reached epidemic proportions throughout the world, with an expected doubling in the number of patients with type 2 diabetes in the next 25 years. This, in turn, will lead to an increased incidence of diabetic nephropathy, with approximately $30 \%$ progressing to stage 5 of chronic kidney disease. The rise may also be due to the development of the above guidelines and simple blood-test-based formulae (eg, eGFR) that allow for easier and earlier diagnosis and, thus, increased reporting. It is worth remembering that most of the formulas for estimating GFR, including the widely used methods of Cockroft and Gault, and the Modification of Diet in Renal Disease (MDRD), ${ }^{19}$ contain age.

In 2006, a group of experts published a revised guideline, called Global Initiative for Chronic Obstructive Lung Disease (GOLD) to update the original version published in 2001. ${ }^{20}$ The 2001 GOLD report classified chronic obstructive pulmonary disease (COPD) into 4 levels, defined using spirometry. Particular emphasis is placed on forced expiratory volume in

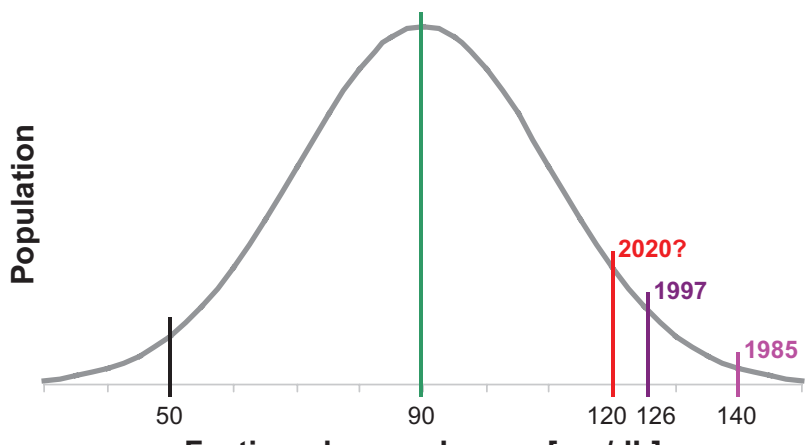

Fasting plasma glucose $[\mathrm{mg} / \mathrm{dL}]$

Figure I Normal data distribution of fasting plasma glucose levels and reporting of diabetes depending on the cutoff points.
1 second $\left(\mathrm{FEV}_{1}\right)$ divided by forced vital capacity (FVC), and on the percentage of the predicted value represented by the $\mathrm{FEV}_{1}$ result. The 2006 report continues to use the same fixed ratio of 0.7 for $\mathrm{FEV}_{1} / \mathrm{FVC}$ (measured after bronchodilator use) to define obstruction. The report mentions that this is a recognized problem, since the ratio decreases as a normal function of aging; using a fixed ratio may lead to overdiagnosis of COPD in older, healthy members of the population, similar to CKD.

These changes in diagnostic criteria have made it difficult, or even impossible, to compare the present statistical data regarding these diseases to historical data for the same illnesses. Due to this difficulty, there is no evidence-based comparison of the prevalence of any disease at present and in the past. Before announcing a global epidemic, a fair epidemiological comparison should be made, based upon the same definitions and using identical diagnostic tools.

On average, people are living longer and diagnostic classifications are broadening. Therefore, the conviction that there is a global epidemic of the most common killers of the 21 st century may be at least partially false, and should be explained to society rather than exclaimed.

\section{Disclosure}

The authors report no conflicts of interest with this work.

\section{References}

1. Epidemic. Available from: www.wikipedia.org/wiki/epidemic.

2. Christensen K, Doblhammer G, Rau R, Vaupel JW. Ageing populations: the challenges ahead. Lancet. 2009;374(9696):1196-1208.

3. World Health Organization. World Health Statistics 2005 [report on the Internet]. Geneva: World Health Organization; 2005. Available from: http://www.who.int/whosis/whostat/whostat2005en.pdf. Accessed November 3, 2011

4. Disease Control Priorities Project [page on the Internet]. Washington, DC: The World Bank., c2006. Available from: http://www.dcp2.org/pubs/ DCP/33/Section/4716. Accessed November 2011.

5. International Diabetes Federation. Diabetes and impaired glucose tolerance. IDF Diabetes Atlas, 4th ed. Brussels, Belgium: International Diabetes Federation, 2009

6. Ryden L, Standl E, Bartnik M, et al: The Task Force on Diabetes and Cardiovascular Diseases of the European Society of Cardiology (ESC) and of the European Association for the Study of Diabetes (EASD). Guidelines on diabetes, prediabetes and cardiovascular diseases. Eur Heart J. 2007;28(1):88-136.

7. Stratton IM, Adler AI, Neil HA, et al. for the United Kingdom Prospective Diabetes Study Group. Association of glycaemia with macrovascular and microvascular complications of type 2 diabetes (UKPDS 35): prospective observational study. BMJ. 2000;321(7258):405-412.

8. Levey AS, Eckardt, K-U, Tsukamoto Y, et al. Definition and classification of chronic kidney disease: a position statement from kidney disease improving global outcomes (KDIGO). Kidney Int [serial on the Internet] 2005;67:2089-2100; Available from: http://www.nature.com/ki/journal/ v67/n6/full/4495286a.html. Accessed November 3, 2011.

9. Raherison C. Epidemiology of COPD. Eur Respir Rev [serial on the Internet]. 2009;18(114):213-221. Available from: http://err.ersjournals. com/content/18/114/213.short. Accessed November 22, 2011. 
10. Fox KA, Birkhead J, Wilcox R, Knight C, Barth J. British Cardiac Society Working Group on the definition of myocardial infarction. Heart. 2004;90(6):603-609.

11. Myocardial infarction redefined - a consensus document of the Joint European Society of Cardiology/American College of Cardiology/ Committee for the redefinition of myocardial infarction. Eur Heart J. 2000;21(18):1502-1513.

12. Thygesen K, Alpert JS, White HD. Joint ESC/ACCF/AHA/WHF Task Force for the redefinition of Myocardial Infarction: Universal definition of myocardial infarction. Eur Heart J. 2007;28(20):2525-2538.

13. World Health Organization. Diabetes mellitus. Report of a WHO study group. Geneva: World Health Organization; 1985. Available from: http:// whqlibdoc.who.int/trs/WHO_TRS_727.pdf. Accessed November 3, 2011.

14. Report of the Expert Committee on the Diagnosis and Classification of Diabetes Mellitus. Diabetes Care. 1997;20(7):1183-1197.

15. National Kidney Foundation. K/DOQI clinical practice guidelines for chronic kidney disease: evaluation, classification, and stratification. $\mathrm{Am}$ J Kidney Dis. 2002;39(2 Suppl 1):S1-S266.
16. National Kidney Foundation. KDOQI clinical practice guidelines for chronic kidney disease: evaluation, classification, and stratification [web page on the Internet]. New York: National Kidney Foundation; 2002. Available from: http://www.kidney.org/professionals/kdoqi/ guidelines_ckd/toc.htm. Accessed November 3, 2011.

17. Lindeman RD, Tobin J, Shock NW. Longitudinal studies on the rate of decline in renal function with age. $J$ Am Geriatr Soc. 1985;33(4):278-285.

18. Coresh J, Astor BC, Greene T, Eknoyan G, Levey AS. Prevalence of chronic kidney disease and decreased kidney function in the adult US population: Third National Health and Nutrition Examination Survey. Am J Kidney Dis. 2003;41(1):1-12.

19. Poggio ED, Nef PC, Wang X, et al. Performance of the Cockroft-Gault and modification of diet in renal disease equations in estimating GFR in ill hospitalized patients. Am J Kidney Dis. 2005;46(2):242-252.

20. GOLD, the Global Initiative for Chronic Obstructive Lung Disease. Available from: www.goldcopd.org. July 6, 2007.

\section{Publish your work in this journal}

The International Journal of General Medicine is an international, peer-reviewed open-access journal that focuses on general and internal medicine, pathogenesis, epidemiology, diagnosis, monitoring and treatment protocols. The journal is characterized by the rapid reporting of reviews, original research and clinical studies across all disease areas.
A key focus is the elucidation of disease processes and management protocols resulting in improved outcomes for the patient.The manuscript management system is completely online and includes a very quick and fair peer-review system. Visit http://www.dovepress.com/ testimonials.php to read real quotes from published authors. 